\title{
Fabrication and Performance Evaluation of Savonious Vertical Axis Wind Turbine for Uncertain Speed Regions
}

\author{
S. Naga Kishore ${ }^{a, *}$, T. Venkateswara Rao ${ }^{b}$, M.L.S. Deva Kumar ${ }^{c}$ \\ ${ }^{a}$ Department of Mechanical Engineering, RSR Engineering College, Kadanuthala, AP, India \\ ${ }^{b}$ Department of Mechanical Engineering, KL University, Vaddeswaram, AP, India \\ ${ }^{c}$ Department of Mechanical Engineering, JNTUCEA, Anantapur, AP, India
}

\begin{abstract}
The consumption of electricity in urban as well as rural is increasing every day and became an essential commodity for household and industrial purposes. Unfortunately the availability of electrical energy in India is not sufficient to the required demand and it is essential to discover and generate energy from non-conventional sources with cheap cost. On the same time it is necessary to reduce the consumption of conventional sources and to save fuel. Among all the renewable resources, wind is one of the best resources available all the time at free of cost. Especially vertical axis wind turbines (VAWT) are self-starting, omni directional. They require no yaw mechanism to continuously orient towards the wind direction and provide a more reliable energy conversion technology, as compared to horizontal axis wind turbine. Particularly savonius vertical axis wind turbines (SVAWT) are suitable and practically possible at low or uncertain wind speed regimes. They can be fitted on rooftops and also suitable for the urban areas where electricity is not available properly. This project deals with the fabrication and performance evaluation of savonius vertical axis wind turbine using two blade rotor. The amount of power developed by the wind turbine is calculated under theoretical and practical conditions and aerodynamics coefficients are also estimated. And various design parameters of savonious rotor are identified and determined.
\end{abstract}

Keywords: Savonious, Vertical Axis Wind turbine, Velocity, Power, Rotor.

\section{Introduction}

Savonius wind turbine is a type of vertical axis wind turbine (VAWT).It consists of number of blades which are connected to rotating shaft usually mounted vertically on the ground surface. It is used for converting the wind force into torque on a rotating shaft. It is not used widely for generating electricity due to low efficiency compared to other types, so it can be employed for other uses, such as pumping water or grinding grain. Most of the swept area near the ground, making the overall energy extraction less effective due to lower wind speed at lower heights. Its best qualities are the simplicity, the reliability and the very low noise production. It can operate well also at low wind speed regions because the torque is very high especially in these conditions however the torque is not constant.

\begin{abstract}
Mohammed Hadi Ali [4] conducted a test in which experiment investigations were carried out to study the performance between two and three blades savonious wind turbine in which blades were designed and fabricated by Aluminum sheet with an aspect ratio of one. The blades were made of semi cylindrical half of diameter and connected to the shaft without overlap. In his study, the savonious turbine used two and three blades which were tested in a subsonic wind tunnel under low wind speed conditions due to many reasons mostly that the savonius wind turbine has its maximum performance and a high starting torque at low wind speed. It was noticed from results that the three blades savonious turbine increased the drag surfaces against the wind air flow and caused to increase the reverse torque and guided to decrease the net torque working on the blades. Hence the three blades savonious wind turbine was less efficient and was having less power coefficient under the same test condition compared to two blades savonious wind turbine. A. A. Kadam et al [1] carried out an experiment in which two and three blades
\end{abstract}

\footnotetext{
${ }^{*}$ Corresponding author. Tel.: +919441875340

E-mail: nagakishore.surisetty@gmail.com

(C) 2016 International Association for Sharing Knowledge and Sustainability

DOI: $10.5383 /$ ijtee. 13.02 .005
} 
used for savonious wind turbine and estimated results under various operating parameters like wind speed, twist angles and tip speed ratio. This study was observed that the rotor without overlap was better in operation than rotor with overlap and two blade rotor was more efficient than three blade rotor. Jean-Luc Menet et al [2] studied the aerodynamic behavior of savonious type wind turbine at low speeds. The fluid flow was estimated by using mathematical simulation by which nature of the flow was defined and power and torque coefficients were calculated along with that most favorable values of geometrical parameters were proposed. And the effect of Reynolds number was studied in the flow. The main aim of the project is to provide electricity using renewable energy sources (wind energy) for the poor families who suffer for electricity in urban and rural areas. The savonious wind power system is constructed at DBS Institute of Technology for uncertain speed region like Kavali, Nellore district, Andhra Pradesh. The performance parameters like power, torque, aerodynamic coefficients and design parameters are determined.

\section{Savonious Wind Turbine Setup}

The rotor specifications are shown in table-1 and design parameters like aspect ratio as 0.667 , overlap ratio as 0.3127 , solidity as 2.667 are taken.

Table-1: Rotor Specifications

\begin{tabular}{|c|c|}
\hline Specification & Value \\
\hline Rotor Diameter (m) D & 1.5 \\
\hline Rotor Height (m) H & 1 \\
\hline Swept Area (m ${ }^{2}$ ) A & 1.5 \\
\hline Chord Length (m) C or d & 1 \\
\hline Shaft diameter (cm) a & 2.5 \\
\hline Overlap Distance (m) e & 0.5 \\
\hline Blade Thickness (mm) t & 1.026 \\
\hline Number of Blades $\mathrm{n}$ & 2 \\
\hline $\begin{array}{c}\text { Wind Speed range at Kavali } \\
\text { region (Miles/Hr) }\end{array}$ & $8-22$ \\
\hline
\end{tabular}

The savonious wind turbine was fabricated with following procedure using above parameters. Hollow metal pipes were taken in required dimensions and cut using bench vice and handsaw. These pipes were welded for preparing base. Aluminum metal sheet was selected for constructing blades. This sheet was bended in semicircular shape and prepared two savonious blades. And finally these blades were fitted to the vertical or main shaft with the help of screw and bolts. The main shaft is turned using lathe up to $0.4 \mathrm{~mm}$ thickness for fixing ball bearings. Bevel gears were used to change the direction of drive in a gear system by 90 degrees. And power is transferred from vertical direction to horizontal direction. Revolutions of horizontal shaft were increased with gear mechanism by which shaft speed was increased to 15 times compared to vertical shaft. The horizontal shaft was connected to DC generator (Dynamo) for converting mechanical energy in to electrical energy. Dynamo or DC generator was connected to battery to store DC energy. The DC energy from battery can be converted in AC energy and used for applications. The experimental setup and energy transformation is as shown in figure- 1 and figure- 2 .

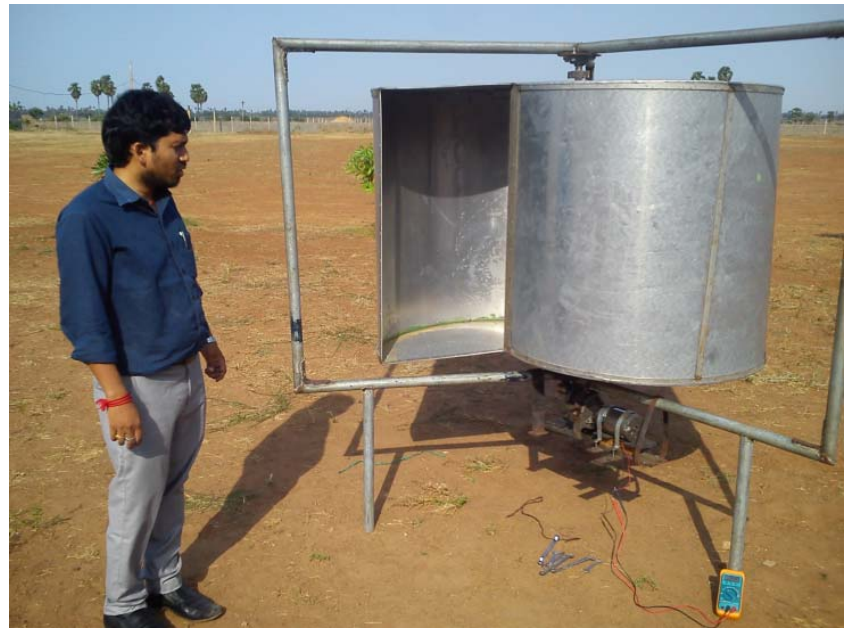

Figure-1. : Savonious Vertical Axis Wind Turbine at DBSIT, Kavali, SPSR Nellore District, AP.

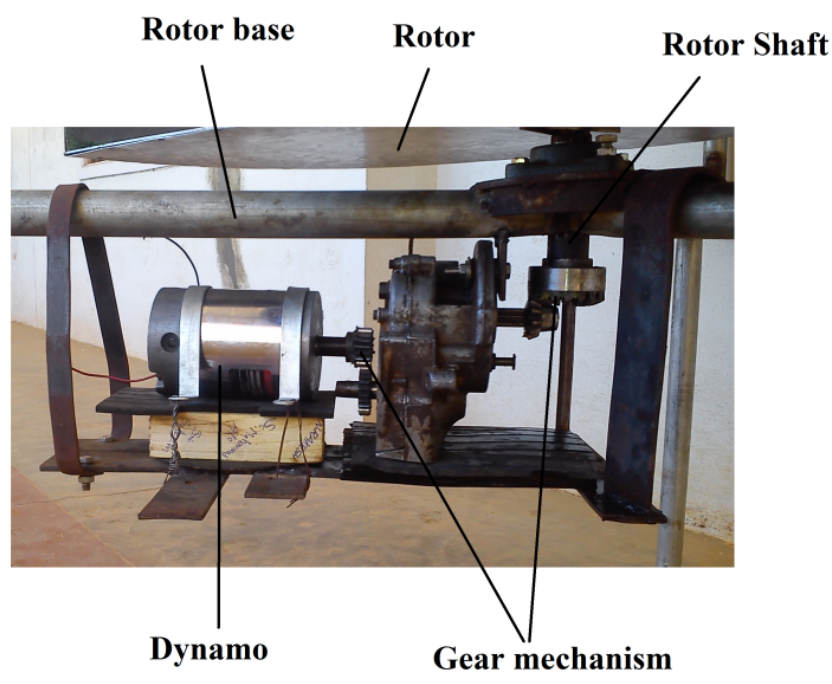

Figure-2: Energy transformation

\section{Performance Evaluation}

The performance of savonious wind turbine can be estimated mainly by torque and power which are developed by rotor. The top view of the wind turbine rotor is as shown in figure-3.

The theoritical torque which is obtained by wind velocity is given by

$$
\mathrm{T}=\quad \rho \mathrm{R}^{2} \mathrm{HV}^{2}
$$

The actual torque developed under practical conditions by rotor is given by [4]

$$
\mathrm{T}_{\mathrm{a}} \quad=\quad \mathrm{I} \boldsymbol{\alpha}
$$

The rotor moment of inertia can be calculated as $\mathrm{I}=\mathrm{Ib}_{\mathrm{b}}+\mathrm{I}_{\mathrm{s}}$

$$
\mathrm{I}_{\mathrm{b}} \quad=\frac{8 \mathrm{~m} \mathrm{~d}^{\wedge} 2}{3 \pi}
$$

The angular acceleration is given as

$$
\alpha=\frac{\omega 2-\omega 1}{\tau}
$$

The torque coefficient is the ratio of actual torque to the theoretical torque and is given by

$$
\mathrm{C}_{\mathrm{m}}=\mathrm{T}_{\mathrm{a}} / \mathrm{T}
$$


The power in the wind can be calculated by using the concepts of kinetics. The wind mill works on the principle of converting kinetic energy of the wind to mechanical energy. The kinetic energy of any particle is equal to one half its mass times the square of its velocity or $1 / 2 \mathrm{mV}^{2}$. The volume of air passing through rotor is product of Area of rotor and Velocity of air. Mass (m) is equal to its Volume flow rate multiplied by its density $(\rho)$ of air and is given by

$$
\mathrm{m}=\rho \mathrm{AV}
$$

The theoretical power of rotor can be written as

$$
\begin{aligned}
\text { Kinetic Energy }=\mathrm{P}=1 / 2 \mathrm{mV}^{2} & =1 / 2 \rho \mathrm{AV} \cdot \mathrm{V}^{2} \text { watts } \\
& =1 / 2 \rho \mathrm{AV}^{3} \text { watts }
\end{aligned}
$$

The above equation tells us that the power available is proportional to air density \& is proportional to the intercept area and velocity. Wind machines intended for generating substantial amounts of power should have large rotors and be located in areas of high wind speed. The wind power in above equation represents the ideal power of a wind turbine, as in case of no aerodynamic or other losses during the energy conversion processes. According to Manwell et al.[15] supported by Jain[14] that, it is not possible for all energy being converted into useful energy due to losses like losses in gearbox, bearings, generator, transmission and others. The power which is available due to losses under practical conditions can be calculated as given below from [4].

The actual power output is given by

$$
\mathrm{P}_{\mathrm{a}}=\mathrm{T}_{\mathrm{a}} \omega_{2}
$$

The is the maximum power coefficient for Savonius rotor is the ratio of Captured mechanical power by blades to the available power in wind.

$$
\mathrm{CP}_{\mathrm{P}} \quad=\quad \mathrm{P} a / \mathrm{P}
$$

' $\mathrm{CP}_{\mathrm{P}}$ ' value represents the part of the total available power that is actually taken from wind and it can be understood as its efficiency. Tip speed ratio, $\lambda$ is defined as the ratio of the linear speed of rotor blade $(\omega . R)$ to the undisturbed wind speed, $V$ from Solanki[12].The other design parameters are aspect ratio, overlap ratio and solidity are from Musgrove [13] given by

$$
\begin{aligned}
& \text { Aspect ratio }(A R)=\frac{\text { rotor height }(H)}{\text { rotor diameter }(\mathrm{D})} \\
& \text { Overlap ratio }(\beta)=\frac{\text { overlap (e)-diameter of the shaft (a) }}{\text { rotor diameter (D) }}
\end{aligned}
$$

$$
\text { Solidity }(\sigma)=\frac{\text { Number of Blades }(\mathrm{n}) \mathrm{X} \text { Chord Legnth }(\mathrm{C})}{\text { radius of rotor }}
$$

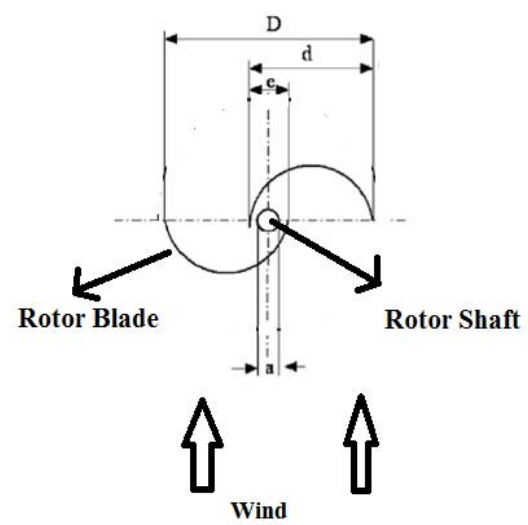

Figure -3: Top view of Savonious rotor

\section{Results and Discussions}

Particularly vertical axis wind turbine was selected for this project instead of HAWT due to low and uncertain wind velocities which are available at Kavali region. Monthly observations were taken for wind velocities at Kavali town. It was noticed that maximum wind velocities are available during $2.30 \mathrm{pm}$ and $5.30 \mathrm{pm}$ particularly due to density differences and available wind velocities ranged in between 8 and 22 Miles/hour which is obtained from weather report. Wind velocity was taken as input for determining theoretical torque and power. But in practical situation, there were number of losses came into consideration like mechanical losses, bearing losses, windage losses and slip losses. The torque and power which were calculated under actual conditions are small than theoretical values. The actual torque was in the range between $38 \%$ and $42 \%$ compared to ideal torque. Similarly the actual power was in the range between $16 \%$ and $27 \%$ compared to theoretical power. It was observed that the losses were increased while increasing the wind speed. The actual power and torque variation with wind speed are shown in figure- 4 and figure-5.

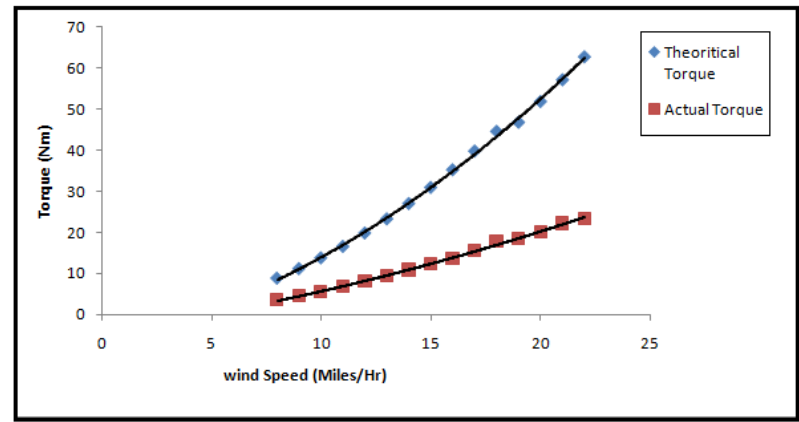

Figure-4: The theoretical and actual torque variation with wind speed 


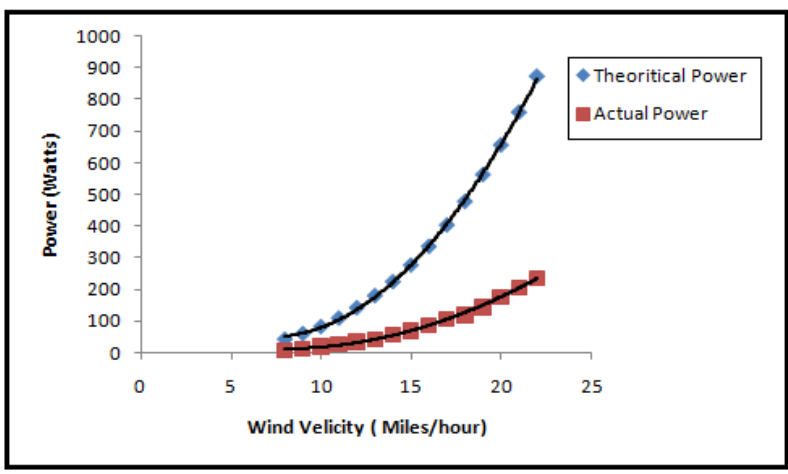

Figure-5: The theoretical and actual power variation with wind speed

Figure- 6 shows that the variation of torque coefficient $\left(\mathrm{C}_{\mathrm{m}}\right)$ and power coefficient $\left(\mathrm{C}_{\mathrm{p}}\right)$ for two blades savonius wind turbine along with wind speed. It was understood that the torque coefficient for two blades was gradually decreasing and power coefficient was increasing when wind speed was increased.

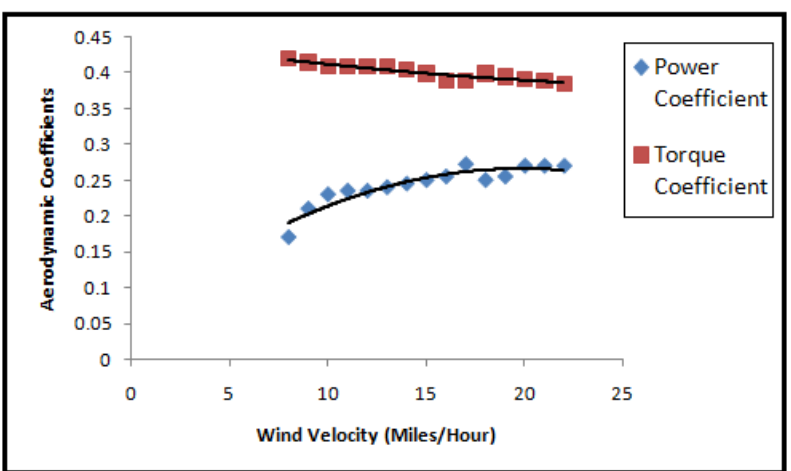

Figure-6: Wind speed Vs Aerodynamic Coefficients

The rotor speed was progressively increased along with wind velocity. The rotor shaft was connected to shaft at dynamo by using gear mechanism by which the shaft speed at dynamo was increased 15 times to that rotor shaft speed as shown in figure7. Figure- 8 explains the variation of tip speed ratio for two blades savonius wind turbine along with wind speed. Graph says that tip speed ratio was gradually increased with wind speed. The angular velocity is directly proportional to the tip speed ratio and the rise in wind velocity increased the rotor speed and angular velocity.

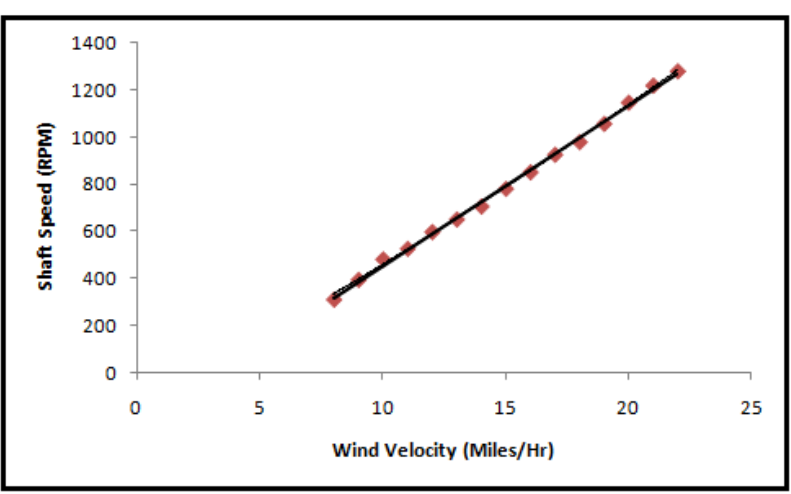

Figure-7: Wind velocity Vs Shaft Speed

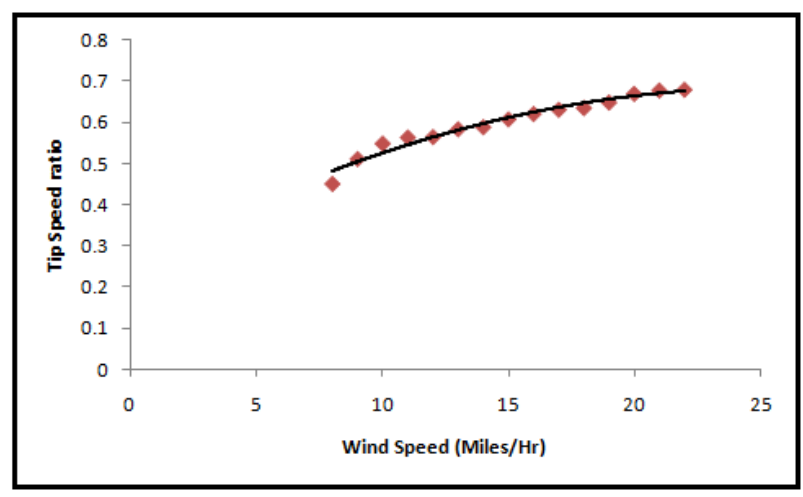

Figure-8: Wind velocity Vs Tip Speed Ratio

\section{Conclusions}

- Wind is one of the best renewable energy resources to produce electricity in the present situation of India. And usage of conventional energy sources can be minimized and fuel consumption can be reduced by using this resource.

- It can be concluded that savonious wind turbine is better alternative for creating electrical energy instead of horizontal axis wind turbines at low or uncertain wind velocity regions like Kavali, SPSR Nellore district, AP.

- $\quad$ Objective of the project was completed in satisfactory way. The savonious vertical axis wind turbine which is constructed at DBS Institute of Technology, Kavali, was produced required amount of actual output which with a poor family can live without paying electricity bill in rural or urban areas.

- $\quad$ The study was shown that the power coefficient increased with the rise in tip speed ratio and rotor speed. The efficiency of the plant varied in between $16 \%$ and $27 \%$ at available velocities.

\section{Acknowledgments}

The authors are thankful to the RSR Engineering College, Kadanuthala, and DBS Institute of Technology, Kavali, for their valuable support in submission of the paper.

\section{Nomenclature}

$\begin{array}{lll}\mathrm{A} & = & \text { Cross sectional area of rotor }\left(\mathrm{m}^{2}\right) \\ \mathrm{AR} & = & \text { Aspect ratio } \\ \mathrm{a} & = & \text { Diameter of shaft }(\mathrm{m}) \\ \mathrm{C} & = & \text { Chord length }(\mathrm{m}) \\ \mathrm{C}_{\mathrm{m}} & = & \text { Torque Coefficient } \\ \mathrm{CP} & = & \text { Power Coefficient } \\ \mathrm{D} & = & \text { Diameter of rotor }(\mathrm{m})\end{array}$




\begin{tabular}{|c|c|c|}
\hline $\mathrm{e}$ & $=$ & overlap (m) \\
\hline $\mathrm{H}$ & $=$ & Height of the rotor $(\mathrm{m})$ \\
\hline I & $=$ & Rotor moment of inertia (Kg. m²) \\
\hline $\mathrm{Ib}_{\mathrm{b}}$ & $=$ & Two blades moment of inertia $\left(\mathrm{Kg} . \mathrm{m}^{2}\right)$ \\
\hline $\mathrm{I}_{\mathrm{S}}$ & $=$ & Shaft moment of inertia $\left(\mathrm{Kg} . \mathrm{m}^{2}\right)$ \\
\hline $\mathrm{m}$ & $=$ & Mass of air $(\mathrm{Kg})$ \\
\hline $\mathrm{N}$ & $=$ & Shaft speed (rpm) \\
\hline $\mathrm{n}$ & $=$ & Number of blades \\
\hline $\mathrm{P}$ & $=$ & Wind Power (Watts) \\
\hline $\mathrm{Pa}$ & $=$ & Actual power (Watts) \\
\hline $\mathrm{R}$ & $=$ & Radius of rotor (m) \\
\hline $\mathrm{T}$ & $=$ & Theoritical torque $(\mathrm{N} \mathrm{m})$ \\
\hline $\mathrm{T}_{\mathrm{a}}$ & $=$ & Actual torque $(\mathrm{Nm})$ \\
\hline $\mathrm{V}$ & $=$ & wind velocity $(\mathrm{m} / \mathrm{s})$ \\
\hline \multicolumn{3}{|c|}{ Greek Symbols } \\
\hline$\rho$ & $=$ & density of air $\left(\mathrm{Kg} / \mathrm{m}^{3}\right)$ \\
\hline$\alpha$ & $=$ & Rotor angular acceleration $\left(1 / \mathrm{s}^{2}\right)$ \\
\hline$\tau$ & $=$ & time $(\mathrm{sec})$ \\
\hline$\omega 1$ & $=$ & Initial angular velocity $(1 / \mathrm{s})$ \\
\hline$\omega 2$ & $=$ & Final angular velocity (1/ s). \\
\hline$\sigma$ & $=$ & Solidity \\
\hline$\beta$ & $=$ & Overlap ratio \\
\hline$\lambda$ & $=$ & Tip speed ratio \\
\hline
\end{tabular}

\section{References}

[1] A. A. Kadam, S.S. Patil, A Review Study on Savonius Wind Rotors for Accessing the Power Performance, 'Second National Conference on Recent Developments in Mechanical Engineering', Pune ,India, pp. 18-24.

[2] Jean-Luc Menet, Nachida Bourabaa, Increase in The Savonius Rotors Efficiency Via A Parametric Investigation, 'ENSIAME', Université de Valenciennes, France.

[3] Manuel Franquesa Voneschen, How to build an energy generator with an old oil barrel without oil (Savonius wind generator), August 19th, 2008.

[4] Mohammed Hadi Ali, Experimental Comparison Study for Savonius Wind Turbine of Two \& Three
Blades At Low Wind Speed, 'International Journal of Modern Engineering Research (IJMER)', Vol. 3, Issue. 5, Sep - Oct. 2013 pp-2978-2986.

[5] P. L. N. V. Aashrith, Ch.Vikranth, Design and Fabrication of Savonious Wind Mill, 'Int. Journal of Engineering Research and Applications', Vol. 4, Issue 6(Version 1), June 2014, pp.70-79.

[6] S. V. Saravanan, M. Varatharaj, L. Ayyadurai, S. Palani \& D. Prem, Design and Fabrication of Vertical Axis Highway Windmill,' International Journal of Advanced Electrical and Electronics Engineering (IJAEEE)', Volume-2, Issue-2, 2013, pp.27-31.

[7] A. A. Kasera, F. X. Ochien'g and R. Kinyua, Development of A Low Cost, Locally Manufactured Rotor Blade for A Savonius Wind Pump,' International Conference on Energy and Environmental Technology', Jomo Kenyatta University of Agriculture \& Technology, Nairobi, Kenya, pp.960-966.

[8] India Wind Energy Outlook-2013, Global Wind Energy Council.

[9] Matthew Burger, Sean Colella, Sean Quinlivan and Joel Rousseau, Construction of a Wind Turbine in the of Florida, MA, 'Project Report for Bachelor of Science, Worcester Polytechnic Institute', March 2007.

[10] Widodo.W.S, Chin.A.C, Haeryip Sihombing and Yuhazri. M.Y., Design and Analysis of $5 \mathrm{KW}$ Savonius Rotor Blade, 'Global Engineers \& Technologists Review', Vol.2, No.8, 2012, pp.1-8.

[11] Akshay Pendharkar, Narayan Komerath, The Low Cost Vertical Axis Wind Turbine Project, 'Proceedings of the 2013 Annual Conference of the American Society for Engineering Education', Atlanta Georgia, June 2013.

[12] Solanki, C.S., Renewable Energy Technologies: A Practical Guide for Beginners, PHI Learning Private Limited, New Delhi, 2009, pp.103-106.

[13] Musgrove, P., Wind Power, UK: Cambridge University Press, 2010.

[14] Jain, P., Wind Energy Engineering, McGraw-Hill, New York, 2011.

[15] Manwell, J.F., McGowan, J.G. and Rogers, A.L., Wind Energy Explained UK, John Wiley \& Son Ltd, 2009.

[16] www.worldweatheronline.com. (http://www.worldweatheronline.com/Kavaliweather/Andhra-Pradesh/IN.aspx) 